\title{
in vitro Antidiabetic and Antioxidant Activities of Aqueous Extract from the Leaf and Fruit of Psidium guajava L.
}

\author{
Adelina Simamora $^{1, *}$, Lusia Paramita ${ }^{1}$, Nur Azreen Binti Mohamad Hamid ${ }^{1}$, \\ Adit Widodo Santoso ${ }^{2}$, Kris Herawan Timotius ${ }^{1}$ \\ ${ }^{1}$ Department of Biochemistry, Krida Wacana Christian University, Jl. Tanjung Duren Raya No. 4, Jakarta, Indonesia \\ ${ }^{2}$ Department of Herbal Medicine Krida Wacana Christian University, Jl. Tanjung Duren Raya No. 4, Jakarta, Indonesia \\ *Corresponding author. E-mail: adelina.simamora@ukrida.ac.id
}

Received date: Oct 10, 2017; Revised date: March 28, 2018; Accepted date: Apr 19, 2018

\section{Abstract}

$\mathrm{B}$ ACKGROUND: The leaf and fruit of Psidium guajava L. are potential for neutraceutical beverage especially for antidiabetic drink. The aims of this study were to determine the antidiabetic activity of aqueous extract of leaf (LE) and fruit (FE) from P. guajava.

METHODS: Both extracts were investigated for their inhibitory effect on $\alpha$-glucosidase activity in vitro. Their antioxidant activities were measured by 2,2-diphenyl-1picrylhydrazyl (DPPH) free radical scavenging, ferrous ion chelating, reducing power and phosphomolybdate methods.

RESULTS: The $\mathrm{IC}_{50}$ of LE, FE and acarbose as a positive control were 5.67, 428.00 and $823.99 \mu \mathrm{g} / \mathrm{mL}$, respectively. The enzyme kinetic analysis indicated that LE inhibited $\alpha$-glucosidase in a competitive inhibition type, similar to that of acarbose. Both extracts showed antioxidant activities, with LE showed stronger activities than FE in all methods.

\section{Introduction}

Diabetes mellitus (DM) is a group of metabolic disorder diseases typified by high level of blood glucose (hyperglycaemia) over a prolonged period. This may be due to either deficiency of insulin secretion (as in type 1 $\mathrm{DM}$ ) or a combination of resistance to insulin action and an inadequate insulin secretion as in type $2 \mathrm{DM}$ (T2DM).(1)
In DPPH method, $\mathrm{IC}_{50}$ of LE and FE were 74.77 and 843.84 $\mu \mathrm{g} / \mathrm{mL}$ respectively, compared to 53.24 and $21.36 \mu \mathrm{g} / \mathrm{mL}$ for reference antioxidants butylated hydroxytoluene (BHT) and ascorbic acid (AA), respectively. In ferrous ion chelating activity, the $\mathrm{IC}_{50}$ were 147.07 and $2105.05 \mu \mathrm{g} / \mathrm{mL}$ for LE and FE, whereas ethylenediaminetetraacetic acid (EDTA) as a control sample was $66.50 \mu \mathrm{g} / \mathrm{mL}$. In reducing power and phosphomolybdate methods, at different concentrations, the activities of LE, FE, and standard compounds showed the following order: $\mathrm{AA}>\mathrm{BHT}>\mathrm{LE}>\mathrm{FE}$.

CONCLUSION: LE from P. guajava exhibited excellent inhibitory activity against $\alpha$-glucosidase. In addition, LE had better antioxidant acivities than FE. This study can recommend the aqueous extract from P. guajava as a promising candidate for neutraceutical drink for prediabetic and diabetic patients.

KEYWORDS: antioxidant, aqueous extract, $\alpha$-glucosidase inhibition, guava, Psidium guajava $\mathrm{L}$.

Indones Biomed J. 2018; 10(2): 156-64

More than $90 \%$ of the diagnosed cases of diabetes in adults is T2DM. Postprandial hyperglycaemia is closely associated with the development of DM and its complications. Glucose in the blood is mainly sourced from hydrolysis of dietary carbohydrates, such as starch. The digestion of the carbohydrates takes place in the lumen of the small intestine in mammals by digestive enzymes to produce glucose. One way of decreasing post prandial hyperglycaemia is by postponing glucose absorption by way of inhibiting the 
digestive enzymes such as $\alpha$-glucosidase. Consequently, inhibitors that target enzymes involved in the digestion of polysaccharides serve as a key strategy in the management of T2DM. Several synthetic $\alpha$-glucosidase inhibitors such as acarbose, voglibose and miglitole are currently used in the treatment of T2DM. However, some unfavourable side effects related to gastrointestinal complications have been reported, such as diarrhoea, abdominal distention and flatulence.(2) Thus, it is essential to search for safer $\alpha$-glucosidase inhibitors which are devoid of adverse side effects of the aforementioned synthetic inhibitors.

One of the major causes of T2DM arises from the damage of pancreatic $\beta$-cells, which are induced by excess free radicals and the resulting oxidative stress. The susceptibility of pancreatic $\beta$-cells to oxidative destruction is also due to the minimum antioxidant defence systems.(3) Therefore, diets containing antioxidant compounds may be helpful in protecting cells from the oxidative damages thus preventing the development of DM and its complications.

Plant materials are good source for neutraceutical drink. Many plant materials have been reported to have inhibitory activities on $\alpha$-glucosidase (4) and antioxidant activities (5). Moreover, several inhibitors on $\alpha$-glucosidase and antioxidant compounds have been successfully isolated from plants to serve as an alternative drug with promising potency and less undesirable side effects than existing drugs.(6)

P. guajava is widely distributed in all tropical and subtropical area. Across the South American and Asian countries including Indonesia, $P$. guajava has been widely used to treat a number of symptoms, mainly for gastrointestinal and respiratory disturbances and antiinflammatory medicine.(7) The leaves are also traditionally used as antidiabetic remedy.(8) The treatments usually involve decoction or infusion of parts of the plant, such as leaf, bark, fruit and shoot. Recent works have reported compounds from guava leaves elucidated using various solvent systems that have antidiabetic and antioxidant properties. These include phenolic and flavonoid compounds (gallic acid, quercetin, kaempferol, guaijaverin, avicularin, myricetin, hyperin and apigenin) and polymerized polyphenol.(9) Despite the numerous traditional use of P. guajava, only a few of these, in particular those involving with water extraction of the plant materials, are supported by scientific evidence. Hence, the objectives of the present study were to determine the $\alpha$-glucosidase inhibitory activity and antioxidant activities from leaves and fruit of P. guajava.

\section{Methods}

\section{Preparation of $P$. guajava Extracts}

The plant materials $P$. guajava were collected in February 2017 from Pagarawan village, Merawang, Bangka, Indonesia and the specimen was authenticated by one of the authors. A herbarium of the plant was kept in the Research Laboratory Centre for Herbal Medicine studies, Krida Wacana Christian University, Jakarta, Indonesia, with voucher specimen number KWF015. Leaves and chopped ripe fruit were dried at room temperature and each was ground into a homogenous powder using a mill. The powder was kept at $4^{\circ} \mathrm{C}$ prior to use.

The extracts were prepared following reported procedure (5) with some modifications. The leaf extract (LE) was prepared by decoction by placing 2 grams of the powder in $200 \mathrm{~mL}$ of deionised hot water at $90^{\circ} \mathrm{C}$. Decoction sample was gently agitated, and the temperature was kept constant to reduce the solvent until half of the starting volume. After filtration, extract was lyophilized with a freeze dryer (MRCFDN-10N-50-BA) to obtain a light brown powder. The procedure was repeated for fruit extract (FE).

\section{Total Phenolic Content}

Total phenolic content of aqueous extracts from P. guajava was determined by Folin-Ciocalteu method (10) with slight modification. An aliquot $(0.5 \mathrm{~mL})$ of samples $(2.02$ and $2.75 \mathrm{mg} / \mathrm{mL}$ for LE and FE, respectively) was mixed with $2.5 \mathrm{~mL}$ of Folin-Ciocalteu (Cat. \#F9252) (Sigma-Aldrich, St Louis, USA) reagent $(10 \%, \mathrm{w} / \mathrm{v})$. The solution was left to stand for 10 minutes at room temperature. The reaction was then neutralized using saturated sodium carbonate (Cat. \#1063860001) (Merck, Darmstadt, Germany) solution $(75 \mathrm{~g} / \mathrm{L})$. After incubation for 2 hours in darkness at room temperature, the absorbance was measured at $765 \mathrm{~nm}$ using spectrophotometer Biochrom Libra S-22 (Biochrom, Cambridge, UK). The total phenolic content was estimated from a standard curve of gallic acid 12.5, 25, 50, 100, and $200 \mu \mathrm{g} / \mathrm{mL}$ (Cat. \#sc205704) (Santa Cruz Biotechnology, Dallas, USA). The results were expressed as mg gallic acid equivalent (mg GAE)/gram dry weight of plant material.

\section{Total Flavonoid Content}

Total flavonoid content was determined using aluminium chloride colorimetric method (11) with slight modification. An aliquot of sample $(0.5 \mathrm{~mL})$ was mixed with $0.15 \mathrm{~mL}$ of $\mathrm{NaNO}_{2}$ (Cat. \#106549) (Merck) solution (5\%, w/v) and 
water $(2 \mathrm{~mL})$. The reaction was incubated for 5 mins and was added with $0.15 \mathrm{~mL}$ of $\mathrm{AlCl}_{3}$ (Cat. \#11019) (SigmaAldrich) solution $(10 \%, \mathrm{w} / \mathrm{v})$. The reaction was incubated for another 5 minutes and was added with $2 \mathrm{~mL}$ of $\mathrm{NaOH}$ (1 M). The mixture was left to stand for 15 minutes at room temperature and the absorbance was read at 510 $\mathrm{nm}$ with spectrophotometer. The total flavonoid content was determined from a rutin (Cat. \#sc204897B) (Santa Cruz Biotechnology) standard curve and the results were expressed as mg rutin equivalent (mg RE)/gram of dry weight of plant material.

\section{a-Glucosidase Inhibitory Activity}

The $\alpha$-glucosidase inhibitory activity of extracts from P. guajava was assayed in vitro according to the literature procedure with some modification.(12) Appropriate dilution of samples $(50 \mu \mathrm{L})$ were mixed with $50 \mu \mathrm{L}$ phosphate buffer (50 mM, pH 6.8), $50 \mu \mathrm{L}$ of $\alpha$-glucosidase (Cat. \#G5003) (Sigma-Aldrich) solution (0.5 unit $/ \mathrm{mL})$. The following concentration ranges were prepared for LE and FE: 3.16, 4.73, 6.31 and $7.89 \mu \mathrm{g} / \mathrm{mL}$ for LE and 137.50, 412.50, 550.00, $687.50 \mu \mathrm{g} / \mathrm{mL}$ for FE. After pre-incubating for 5 minutes at $37^{\circ} \mathrm{C}, 100 \mu \mathrm{L}$ of $1 \mathrm{mM}$ p-nitrophenyl- $\alpha$-D-glucopyranoside (Cat. \#N1377) (Sigma-Aldrich) as a substrate was added to the reaction mixture and the reaction was further incubated for 20 minutes at $37^{\circ} \mathrm{C}$. The reaction was terminated by the addition of $750 \mu \mathrm{L}$ of $\mathrm{Na}_{2} \mathrm{CO}_{3}(100 \mathrm{mM})$. The $\alpha$-glucosidase inhibitory activity was determined spectrophotometrically by measuring the amount of p-nitrophenol released from the substrate at $405 \mathrm{~nm}$. The inhibition percentage was calculated using the following equation:

$\%$ inhibition of $\alpha$-Glucosidase $=$ A control-A sample x 100\% A control

Where A control: absorbance of control, A sampel: absorbance of sample. The $\alpha$-glucosidase inhibitory activity was expressed as inhibitory concentration (IC) $)_{50}$ values ( $\mu \mathrm{g}$ / $\mathrm{mL}$ ) and was determined from the graph plotted against the percentage inhibition. Values were compared with the positive control acarbose United States Pharmacopeia (USP) (Cat. \#1000521) (Sigma-Aldrich) the antidiabetic medicine.

\section{Kinetics Inhibition Mode}

The mode on inhibition of $\alpha$-glucosidase by LE was determined using a Lineweaver-Burk plot.(13) The kinetics assay was performed using increasing concentrations of the substrate p-nitrophenyl- $\alpha$-D-glucopyranoside $(0.15$ - $1 \mathrm{mM})$.
Substrate was incubated with $\alpha$-glucosidase in the absence of inhibitor and presence of LE at different concentrations (0 to $4.21 \mu \mathrm{g} / \mathrm{mL})$. A double reciprocal plot (1/[S] and 1/V) was constructed based on the Lineweaver-Burk. The mode of inhibition was compared with that of the positive control acarbose.

\section{2,2-diphenyl-1-picrylhydrazyl (DPPH) Radical Scavenging Activity}

The free-radical scavenging capacity of extracts from P. guajava was evaluated using DPPH stable radical following reported method (14) with minor modification. The assay is based on the ability of a substrate to donate a hydrogen atom in order to scavenge the DPPH radical. DPPH (Cat. \#D9132) (Sigma-Aldrich) solution (0.6 mM in ethanol) was prepared and $1 \mathrm{~mL}$ of this solution was added to $3 \mathrm{~mL}$ of sample in various concentration; 16.83 , 25.25, 33.67, 42.08, 50.50, 67.33 and $84.17 \mu \mathrm{g} / \mathrm{mL}$ for $\mathrm{LE}$ and $91.67,183.33,366.67,458.33,641.67$ and $916.67 \mu \mathrm{g} /$ $\mathrm{mL}$ for FE. The mixture was immediately vortexed and incubated for 30 minutes in darkness at room temperature. The decrease in absorbance was measured at $517 \mathrm{~nm}$ using spectrophotometer. The percentage of inhibition activity was calculated according to the following equation:

$$
\% \text { Inhibition }=\frac{\mathrm{A} \text { control-A sample }}{\mathrm{A} \text { control }} \times 100 \%
$$

The concentration of the sample and the reference required to scavenge $50 \%$ of the DPPH radical was defined as $\mathrm{IC}_{50}$ and was determined by the graph plotting against percentage of inhibition. The values were expressed as $\mu \mathrm{g} / \mathrm{mL}$ and values were compared with those of reference solutions i.e., butylated hydroxytoluene (BHT) (Cat. \#B1378) (SigmaAldrich) and ascorbic acid (Cat. \#470300-286) (VWR BDH Prolabo Chemicals, Tingalpa, Australia).

\section{Ferrous Ion Chelating Activity}

The ability of aqeuous extract from P. guajava and standard to chelate iron(II) was estimated according to the method (15) in the literature. Concentrations of the extracts were $37.88,75.75,151.50,227.25$ and $303.00 \mathrm{ug} / \mathrm{mL}$ for LE and $343.75,687.50,1031.25,1375.00,1718.75$ and $2200.00 \mathrm{ug} / \mathrm{mL}$, for FE. In this method, $0.4 \mathrm{~mL}$ extract and ethylenediaminetetraacetic acid (EDTA) (Cat. \#E164) (Sigma-Aldrich) at various concentrations (20, 100, 200 and $400 \mathrm{ug} / \mathrm{mL}$ ) were added with $0.5 \mathrm{~mL} \mathrm{FeSO}_{4}$ (Cat. \#103965) (Merck) solution $(0.2 \mathrm{mM})$. To start the reaction, $0.2 \mathrm{~mL}$ ferrozine (Cat. \#82950) (Sigma-Aldrich) solution (0.5 mM) 
was added and the total volume was adjusted to $4 \mathrm{~mL}$ with water. The reaction was immediately vortexed and was left to stand in the dark at room temperature for 10 minutes. The absorbance was read at $562 \mathrm{~nm}$ using spectrophotometer. Iron chelating ability was calculated using the following equation:

Ferrous ion chelating $=$ A control-A sample $\mathrm{x} 100 \%$

$$
\text { activity (\%) A control }
$$

Where A control: absorbance of control, A sample: absorbance of the sample. The concentration of extracts required to chelate $50 \%$ of the $\mathrm{Fe}(\mathrm{II})$ ion $\left(\mathrm{IC}_{50}\right)$ was calculated from the graph plotted against the percentage of inhibition. The $\mathrm{IC}_{50}$ value was expressed as $\mu \mathrm{g} / \mathrm{mL}$ and values were compared with the standard EDTA.

\section{Reducing Power Activity}

Reducing power capacity was determined using method previously reported (15) with slight modification. Different concentrations of $P$. guajava extracts and standards (ascorbic acid and BHT) in water (50, 100 and $200 \mu \mathrm{g} /$ $\mathrm{mL}$ ) were prepared and $1 \mathrm{~mL}$ of each sample solution was mixed with $2.5 \mathrm{~mL}$ phosphate buffer (200 mM, pH 6.6) and $2.5 \mathrm{~mL} \mathrm{~K}_{3} \mathrm{Fe}(\mathrm{CN})_{6}$ (Cat. \#104971) (Merck) solution $(1 \% \mathrm{w} / \mathrm{v})$. The mixture was incubated in a water bath for 20 minutes at $50^{\circ} \mathrm{C}$. Trichloroacetic acid (Cat. \#T6399) (Sigma-Aldrich) solution $(2.5 \mathrm{~mL}, 10 \% \mathrm{w} / \mathrm{v})$ was added to the mixture and centrifuged for 10 minutes at $3000 \mathrm{rpm}$. The upper layer of the solution $(2.5 \mathrm{~mL})$ was taken out and mixed with water $\left(2.5 \mathrm{~mL}\right.$ ) and $\mathrm{FeCl}_{3}$ (Cat. \#sc215192) (Santa Cruz Biotechnology) solution $(0.5 \mathrm{~mL}, 0.1 \% \mathrm{w} / \mathrm{v})$. The absorbance of each sample was read at $700 \mathrm{~nm}$ by spectrophotometer and was compared with the standards.

\section{Total Antioxidant Activity/Phosphomolydate Method}

Total antioxidant capacity of extracts from $P$. guajava was estimated using a phosphomolybdate method (16) reported in the literature. Reagent solution was prepared containing sulfuric acid $(0.6 \mathrm{M})$, sodium phosphate $(28 \mathrm{mM})$ and ammonium molybdate (Cat. \#101182) (Merck) solution (4 $\mathrm{mM}) .3 \mathrm{~mL}$ of this solution was added to $0.3 \mathrm{~mL}$ extract solution and standards (ascorbic acid and BHT) in water $(50,100,200$ and $400 \mu \mathrm{g} / \mathrm{mL})$ placed in capped tubes. Reaction mixture was incubated in water bath at $95^{\circ} \mathrm{C}$ for 1.5 hours and it was let to cool at room temperature. The absorbance was measured at 695 using spectrophotometer and was compared with the standards.

\section{Statistical Analysis}

All experiments were carried out in triplicates. Results were reported as mean \pm standard deviation (SD). Regresion method was used to calculate $\mathrm{IC}_{50}$ and enzymatic kinetic. Significance differences among the means values were analysed using Duncan's multiple range test. Values of $p<0.05$ were regarded as significant.

\section{Results}

\section{Phenolic and Flavonoid Content}

The total phenolic content of the extracts was estimated from a gallic acid standard curve using the following correlation equation of $y=0.0084 x+0.0478$ (a correlation coefficient of $\left.\mathrm{R}^{2}=0.9977\right)$. The total flavonoid content of the extracts was estimated from a rutin standard curve using the correlation equation of $\mathrm{y}=0.001 \mathrm{x}+0.0066$ (a correlation coefficient of $\left.\mathrm{R}^{2}=0.9999\right)$. The total phenolic and flavonoid content for LE and FE was shown in Table 1. LE was found to contain a much higher phenolic content when compared with FE; 114.81 and $17.86 \mathrm{mg}$ GAE/g dry weight for LE and FE, respectively. Similarly, LE was observed to have a considerably higher flavonoid content than FE, which were 152.17 and $19.88 \mathrm{mg}$ RE/gram dry weight for LE and FE, respectively.

Table 1. Total phenolic and flavonoid content of aqueous extracts from $P$. guajava.

\begin{tabular}{lcccc}
\hline & \multicolumn{2}{c}{ Total Phenolic Content } & \multicolumn{2}{c}{ Total Flavonoid Content } \\
\cline { 2 - 5 } & $(\mathbf{m g ~ G A E} / \mathbf{g}) *$ & $(\boldsymbol{\mu g}$ GAE$/ \mathbf{m L}) *$ & $(\mathbf{m g ~ R E} / \mathbf{g}) * *$ & $(\boldsymbol{\mu g ~ R E} / \mathbf{g}) * *$ \\
\hline Leaf extract & $114.81 \pm 8.25$ & $1148.09 \pm 82.48$ & $152.17 \pm 2.64$ & $1521.73 \pm 26.38$ \\
Fruit extract & $17.86 \pm 0.25$ & $178.56 \pm 2.47$ & $19.88 \pm 0.34$ & $198.83 \pm 3.41$ \\
\hline
\end{tabular}

*Total phenolic content was analysed as mg GAE/g dry weight of plant material and $\mu \mathrm{g} \mathrm{GAE} / \mathrm{mL}$; values are mean $\pm \mathrm{SD}(\mathrm{n}=3)$. GAE: gallic acid equivalent.

**Total flavonoid content was analysed as mg RE/g dry weight of plant material and $\mu \mathrm{g} \mathrm{RE} / \mathrm{ml}$; values are mean $\pm \mathrm{SD}(\mathrm{n}=3)$. RE: rutin equivalent.

\section{Inhibition of $\alpha$-Glucosidase}

As shown in Table 2, both the extracts inhibited $\alpha$-glucosidase in a concentration-dependent manner. Both extracts exhibited marked inhibition against $\alpha$-glucosidase, with $\mathrm{IC}_{50}$ values much lower than acarbose; 5.67 and 428.00 $\mu \mathrm{g} / \mathrm{mL}$ for LE and FE, respectively, and acarbose $823.99 \mu \mathrm{g} /$ mL. It was evident that LE possessed a stronger inhibitory effect on the enzyme than FE. The type of inhibition was competive (Figure 1). 
Table 2. $\alpha$-Glucosidase inhibitory activities of aqueous extracts from $P$. guajava.

\begin{tabular}{lccc}
\hline & $\begin{array}{c}\text { Concentration } \\
(\boldsymbol{\mu g} / \mathbf{m L})\end{array}$ & $\begin{array}{c}\text { Inhibition } \\
(\%)\end{array}$ & $\begin{array}{c}\mathbf{I C}_{\mathbf{5 0}} \\
(\boldsymbol{\mu g} / \mathbf{m L})\end{array}$ \\
\hline Leaf Extract & 3.16 & $14.01 \pm 1.91$ & \\
& 4.73 & $35.35 \pm 15.25$ & $5.67 \pm 0.34$ \\
& 6.31 & $60.87 \pm 7.96$ & \\
Fruit Extract & 7.89 & $82.94 \pm 3.38$ & \\
& 137.5 & $7.74 \pm 2.60$ & \\
& 412.5 & $53.39 \pm 4.19$ & $428.00 \pm 2.30$ \\
& 550.0 & $70.14 \pm 3.39$ & \\
Acarbose & 687.5 & $78.68 \pm 3.12$ & \\
& 150 & $15.98 \pm 9.53$ & \\
& 250 & $19.10 \pm 2.11$ & \\
& 500 & $34.68 \pm 0.97$ & \\
\hline
\end{tabular}

\section{Antioxidant Activities}

Four methods were used in this study to evaluate the antioxidant activities. DPPH assay was the method used to evaluate the radical scavenging activity of the extracts. Both $\mathrm{LE}$ and FE were able to scavenge the DPPH radicals, with activities weaker than the standards (Table 3); $\mathrm{IC}_{50}$ of 74.77 and $843.84 \mu \mathrm{g} / \mathrm{mL}$ for LE and FE, compared with 53.24 and $21.36 \mu \mathrm{g} / \mathrm{mL}$ for ascorbic acid and BHT, respectively. However, it is worth pointing that LE exhibited more effective scavenging activity than FE.

The ferrous ion chelating activities of extracts and standard are presented in Table 3. Both LE and FE showed low chelating activity for ferrous ion compared with the standard chelator $\mathrm{Na}_{2}$ EDTA; $_{\mathrm{IC}_{50}}$ of 147.07 and $2105.05 \mu \mathrm{g} /$ $\mathrm{mL}$ for $\mathrm{LE}$ and $\mathrm{FE}$, compared with 66.50 for $\mathrm{Na}_{2}$ EDTA.
Table 3. DPPH radical scavenging and ferrous ion chelating activities of aqueous extracts from $P$. guajava and standards.

\begin{tabular}{lcc}
\hline & \multicolumn{2}{c}{ IC $_{\mathbf{5 0}}(\boldsymbol{\mu g} / \mathbf{m L})$} \\
\cline { 2 - 3 } & $\begin{array}{c}\text { DPPH radical } \\
\text { scavenging }\end{array}$ & $\begin{array}{c}\text { Ferrous ion } \\
\text { chelating }\end{array}$ \\
\hline Leaf extract & $74.77 \pm 5.26$ & $147.07 \pm 13.95$ \\
Fruit extract & $843.84 \pm 9.52$ & $2105.05 \pm 58.57$ \\
Ascorbic acid & $53.24 \pm 0.82$ & $\mathrm{NA}$ \\
BHT & $21.36 \pm 0.80$ & $\mathrm{NA}$ \\
EDTA & $\mathrm{NA}$ & $66.5 \pm 1.02$ \\
\hline
\end{tabular}

Values are mean $\pm \mathrm{SD}(\mathrm{n}=3)$

NA: not assayed

The reducing power assay assesses antioxidant potential by measuring the reduction of $\mathrm{Fe}$ (III) to $\mathrm{Fe}$ (II) in the presence of antioxidant compounds in the extract. The potassium ferricyanide reducing assay was used to this end, and the results are shown in Figure 2a. The absorbance of LE and standards at $700 \mathrm{~nm}$ increased with increasing concentrations of the samples ( 50 to $200 \mu \mathrm{g} / \mathrm{mL}$ ), suggested an increased in reducing ability. At 50 and $100 \mu \mathrm{g} / \mathrm{mL}$, LE showed an effective reducing power, similar with the standard BHT (the difference is not statistically significant). However, weaker activity was observed when compared with ascorbic acid. LE reducing activity is observed to be stronger than BHT at $200 \mu \mathrm{g} / \mathrm{mL}(p<0.05)$. In contrast, FE did not show significant reducing activity.

The phosphomolybdate assay assesses the total antioxidant capacity in term of the reductive activity of both phenolics and non-phenolics compounds, such as ascorbic acid, tocopherol, etc. As can be seen in Figure 2b, at the range of 50 to $400 \mu \mathrm{g} / \mathrm{mL}$, the extracts and standards exhibited an increased in absorbance, indicating an increased reduction

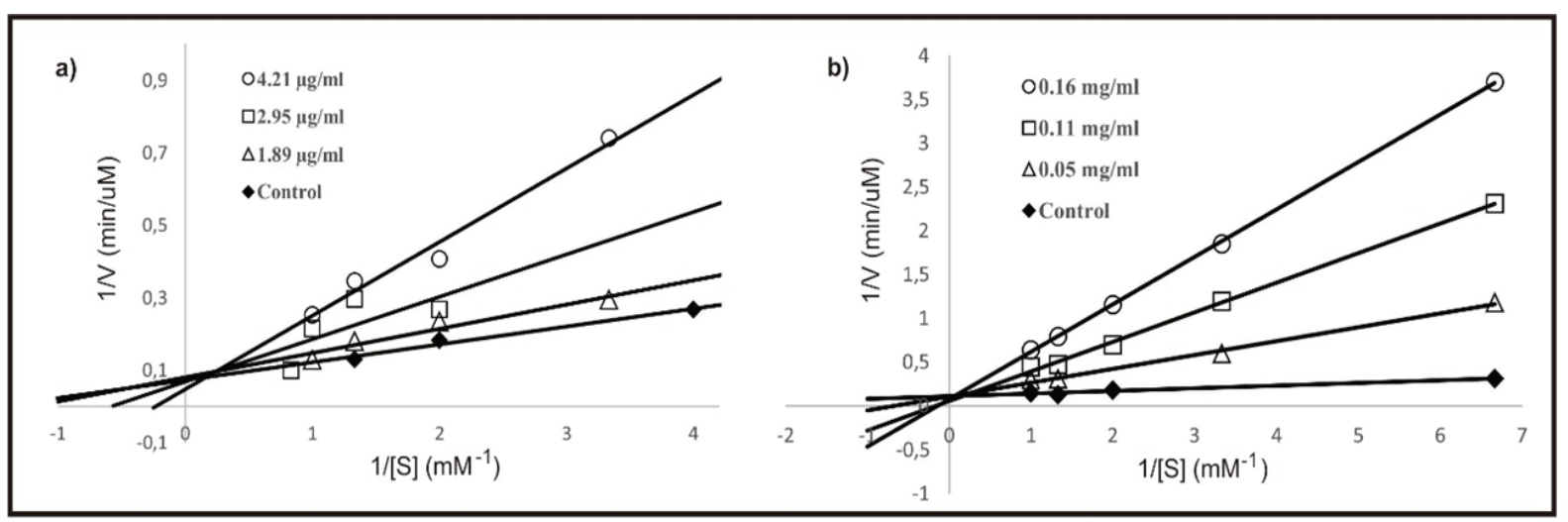

Figure 1. Kinetics of inhibition on $\alpha$-glucosidase by aqueous leaf extract of $P$. guajava (a) and acarbose (b). 


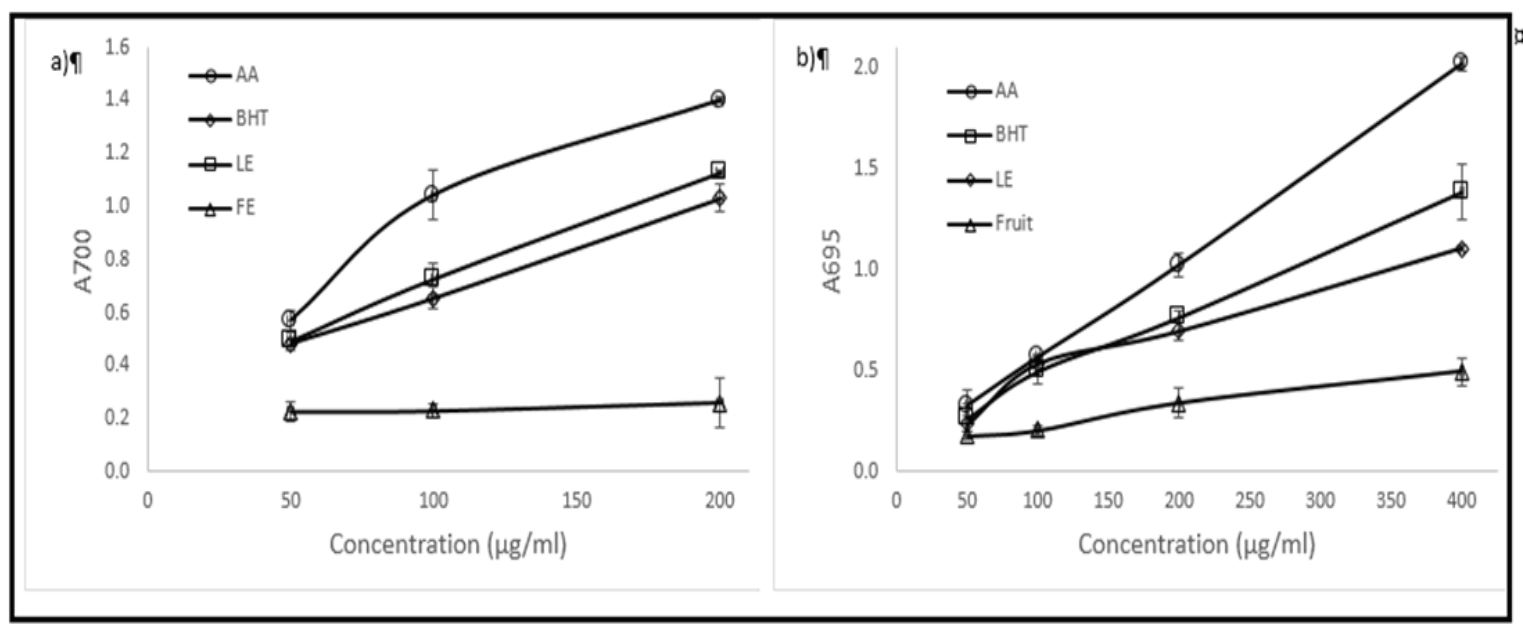

Figure 2. Reducing activities of aqueous extracts from $P$. guajava and standards as measured by reducing power method (a) and phosphomolybdate method (b). AA: ascorbic acid, BHT: butylated hydroxytoluene, LE: leaf extract, FE: fruit extract. Values are mean of three measurements.

of $\mathrm{Mo}(\mathrm{VI})$ to $\mathrm{Mo}(\mathrm{V})$ by the antioxidant compounds in the tested materials. Overall, LE has lower activity than the standards ascorbic acid and BHT $(p<0.05)$. However, at the concentration of $100 \mu \mathrm{g} / \mathrm{mL}$, LE exhibited stronger reducing ability than ascorbic acid exhibited $(p<0.05)$. The reducing ability for LE was lower than standards at concentrations 200 and $400 \mu \mathrm{g} / \mathrm{mL}(p<0.05)$. Similarly to those found in the reducing power assay, FE did not show substantial reducing activity, observing no modulation in absorbance with increasing concentrations.

\section{Discussion}

As can be seen from the results above, LE had stronger biological activities when compared with FE, in terms of its inhibitory activity on $\alpha$-glucosidase and antioxidant activity. These differences were probably due to that LE containing more concentrated bioactive compounds that FE. Many studies have shown that bioactivities of plant materials are closely related to their phenolic type compounds. $(5,17)$ To this end, we have evaluated the polyphenolics content in the aqueous extracts from $P$. guajava by measuring their phenolic content, expressed as GAE, and flavonoid content, expressed as RE. LE had higher total phenolic and flavonoid content than those observed for FE. The higher levels of polyphenolics found in LE than FE is consistent with other previous reports. $(7,18)$ High biological activities may be attributed to polyphenolic compounds in the extracts. Results obtained from this study offer a valid starting point for the exploitation of P. guajava for use as antidiabetic and antioxidant natural source. Isolation and identification of active chemical constituents could be the direction of future studies.

The study herein was designed to investigate the antidiabetic potentials from the natural derived products with increased potency and less side effects than that of the synthetic inhibitors. In the present work, the $\alpha$-glucosidase inhibitory activity of aqueous extracts from $P$. guajava has been investigated. Results reveal that both LE and FE exerted remarkable inhibitory effect on $\alpha$-glucosidase when compared with acarbose. The LE, however, was observed to have a stronger inhibitory activity than FE. Marked difference in inhibitory activities between the two extracts is probably related to the difference in their polyphenolic compound contents, as shown from their total phenolic and flavonoid content. Previous studies on $\alpha$-glucosidase inhibitors isolated from medicinal plants suggest that some potential inhibitors belong to phenolic type group, including flavonoid class, have features inhibiting $\alpha$-glucosidase activity. $(19,20)$

A number of previous studies have reported more potent $\alpha$-glucosidase inhibitory activities from plant extracts compared to acarbose. Water extract from Brickellia cavanillesii was reported to have a stronger activity compared to acarbose $\left(\mathrm{IC}_{50}\right.$ extract $0.169 \mathrm{mg} / \mathrm{mL}$ and acarbose $1.12 \mathrm{mg} / \mathrm{mL}$ ).(21) In another study, several Echeveria species extracted with methanol were found to be more active than acarbose $\left(\mathrm{IC}_{50}\right.$ of E. subrigida, E. kimnachii and E. craiginia were $0.025,0.057$ and 0.051 $\mathrm{mg} / \mathrm{mL}$, respectively, whereas acarbose $3.59 \mathrm{mg} / \mathrm{mL}$ ).(22) Furthermore, it was reported that Polygonum senegalensis 
and Pseudocedrela kotschyi exhibited better activities than acarbose $\left(\mathrm{IC}_{50}\right.$ extracts $1.5 \mu \mathrm{g} / \mathrm{mL}$ and $5 \mu \mathrm{g} / \mathrm{mL}$, respectively, whereas acarbose $0.726 \mathrm{mg} / \mathrm{ml}) .(23)$

Kinetic study was conducted to understand the mode of inhibition on $\alpha$-glucosidase by P. guajava extract. The study has been carried out for LE, which has the strongest inhibitory activity. The result was compared with the standard drug, acarbose. Figure 1 shows the double reciprocal plot of the inhibition. The plot generated straight lines which had different intersections in the $\mathrm{x}$-axis. This indicates that the mode of $\alpha$-glucosidase inhibition by LE is of competitive mode, similar to that of acarbose. This could suggest that the extract inhibited $\alpha$-glucosidase by binding with the free enzyme in a manner that prevents substrate binding.

In the living system, hyperglycaemic condition often leads to stress oxidative. Antioxidant in the diets may help protect against oxidative damages. In this direction, antioxidant potential of the extracts was also investigated. Due to the multiple ways in which antioxidant protect biological systems, various methods were employed in assessing antioxidant activity, as to determine the reactions that may contribute to the antioxidant potential of the extracts. These methods include assays evaluating the radical scavenging activity, metal chelating ion ability, and reducing ability. One of the pathways of antioxidant mechanism of action is by removing free radicals. This can be achieved by donating hydrogen to free radicals, leading to the formation of unreactive species. For the evaluation of radical scavenging activity, we have used DPPH radical scavenging assay, as the DPPH molecule is considered to be a model of lipophilic radicals formed by lipid auto oxidation.(24) The results reveal that both LE and FE exhibited activities in scavenging DPPH radicals, in particular LE, observing noticeable activity when compared with the standard ascorbic acid. The scavenging activity may be related to their phenolic and flavonoid content. The stronger radical scavenging activity was observed for LE which has higher phenolic and flavonoid content compared with FE. In this sense, we attempted to find a correlation between antioxidant activities with the phytochemical contents. It can be seen in Figure 3 that there is a significant linear correlation between the DPPH radical scavenging activity ( $\%$ of inhibition) and total phenolic ( $\mu \mathrm{g}$ GAE/ $\mathrm{mL})$ and flavonoid $(\mu \mathrm{g} \mathrm{RE} / \mathrm{mL})$ compounds $\left(\mathrm{R}^{2}=0.8301\right.$ and 0.7413 for phenolic and flavonoid, respectively). This finding provides evidence that polyphenols in the extract are likely to contribute to the radical scavenging activities in LE. This result is in agreement with the previous report for the strong relationship between antioxidant activities and polyphenolics in medicinal plants.(17) The structural features of the phenolic compounds may be responsible for the activity, due to the ease of proton donation from phenolic structure and the nucleophilic character of the benzene ring. Radical reactions can be initiated by the presence of transition metal ions, such as $\mathrm{Cu}(\mathrm{I})$ and $\mathrm{Fe}(\mathrm{II})$ ions. These metal ions is able to participate in a one-electron transfer reaction that generate ROS, such as $\bullet \mathrm{OH}$ from $\mathrm{H}_{2} \mathrm{O}_{2}$ through the Fenton reaction.(25) Thus, ability to chelate transition metal ions is an important antioxidant property and measuring chelation of ferrous ion is one method to evaluate this property. It was evident that both extracts were able to chelate Fe(II) ion, however their binding activities were weak compared with the standard EDTA. Between these two extracts, LE was found to have much higher activity than FE. As in the radical scavenging assay, this result was in accordance with the phytochemical content of the extracts, i.e., phenolic and flavonoid compounds. This findings were in agreement
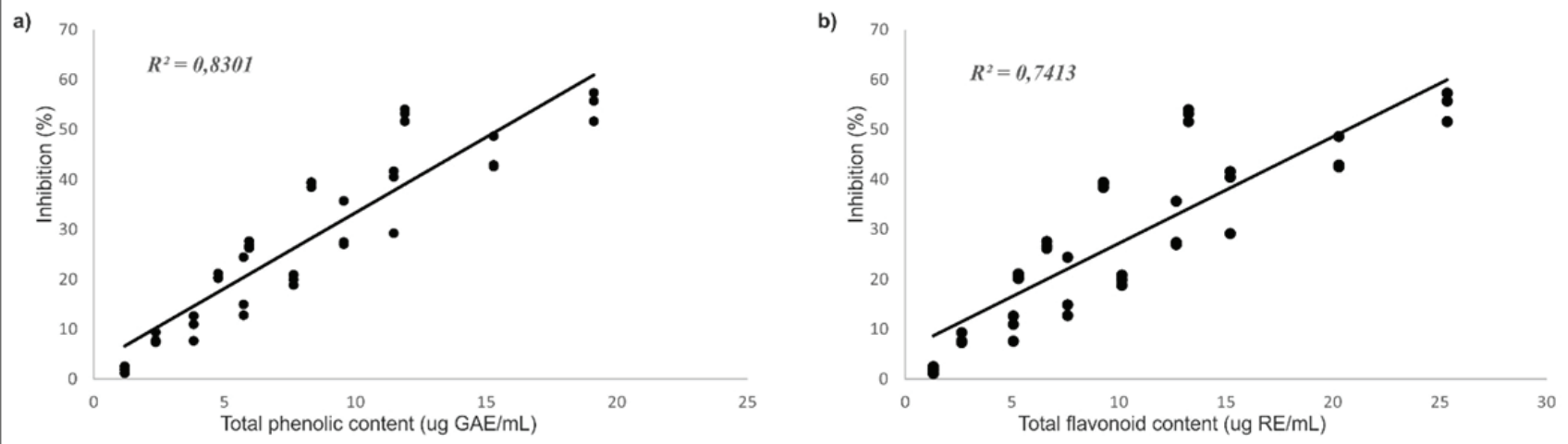

Figure 3. Correlation between DPPH inhibition (\%) and total phenolic compound ( $\mu \mathrm{g}$ GAE/mL) (a) and between DPPH inhibition (\%) total flavonoid content ( $\mu \mathrm{g} \mathrm{RE} / \mathrm{mL})$ of aqueous extracts from P. guajava (b). 
with the reported studies for the chelating activities of the polyphenolic class compounds.(26,27) The mechanism that is operative may be through the formation of bidentate complexes between $\mathrm{Fe}(\mathrm{II})$ ion and the poly hydroxyl structure in the polyphenolics.

Studies have reported that the antioxidant effect is concomitant with development of reducing power and that the antioxidant properties is associated with the presence of reductones.(28) In this direction, we have investigated the reducing capacity of our extracts. Herein, LE was again showed stronger reductive activity than FE using the ferricthiocyanate method. The result is similar to that found for total antioxidant activity based on the phosphomolybdate method. The observed differences between LE and FE may be attributed to the content of polyphenolic compounds. This may suggest that polyphenols in the extract may act as electron donor, reacting with free radicals to terminate the chain reaction.

\section{Conclusion}

Aqueous extracts of leaf and fruit from $P$. guajava are good sources for neutraceutical material. Their antidiabetic activities are excellent. The study found that LE is better than FE in their antioxidant activities. Results obtained from this study offer a valid starting point for the exploitation of P. guajava for use as antidiabetic and antioxidant natural source. However, further studies are necessary in order to confirm their biological activities in different in vivo system, along with their mode of action.

\section{Acknowledgment}

We acknowledged funding from the Research Institution in the Faculty of Medicine Krida Wacana Christian University. We thank Mrs. Tjhia Lie Hwa from Pagarawan village, Bangka Island, Indonesia for kindly providing us with the plant materials.

\section{References}

1. Cefalu WT. Diagnosis and classification of diabetes mellitus. Diabetes Care. 2004; 27(Suppl 1): s5-10.

2. Kim JG, Jo SH, Ha KS, Kim SC, Kim YC, Apostolidis E, et al. Effect of long-term supplementation of low molecular weight chitosan oligosaccharide (GO2KA1) on fasting blood glucose and $\mathrm{HbA} 1 \mathrm{c}$ in $\mathrm{db} / \mathrm{db}$ mice model and elucidation of mechanism of action. BMC Complement Altern Med. 2014; 14: 272. doi: 10.1186/1472-688214-272.

3. Li N, Frigerio F, Maechler P. The sensitivity of pancreatic $\beta$-cells to mitochondrial injuries triggered by lipotoxicity and oxidative stress. Biochem Soc Trans. 2008; 36: 930-4.

4. Hung HY, Qian K, Morris-Natschke SL, Hsu CS, Lee KH. Recent discovery of plant-derived anti-diabetic natural products. Nat Prod Rep. 2012; 29: 580-606.

5. Katalinic V, Milos M, Kulisic T, Jukic M. Screening of 70 medicinal plant extracts for antioxidant capacity and total phenols. Food Chem. 2006; 94: 550-7.

6. Matsuda H, Asao Y, Nakamura S, Hamao M, Sugimoto S, Hongo M, et al. Antidiabetogenic constituents from the Thai traditional medicine Cotylelobium melanoxylon. Chem Pharm Bull. 2009; 57: 487-94.

7. Gutiérrez RMP, Mitchell S, Solis RV. Psidium guajava: a review of its traditional uses, phytochemistry and pharmacology. J Ethnopharmacol. 2008; 117: 1-27.

8. Giovannini P, Howes MJR, Edwards SE. Medicinal plants used in the traditional management of diabetes and its sequelae in Central America: A review. J Ethnopharmacol. 2016; 184: 58-71.

9. Díaz-de-Cerio E, Verardo V, Gómez-Caravaca AM, FernándezGutiérrez A, Segura-Carretero A. Health effects of Psidium guajava L. Leaves: An overview of the last decade. Int J Mol Sci. 2017; 18: pii: E897. doi: 10.3390/ijms18040897.

10. Ahmed D, Fatima K, Saeed R. Analysis of phenolic and flavonoid contents, and the anti-oxidative potential and lipid peroxidation inhibitory activity of methanolic extract of Carissa opaca roots and its fractions in different solvents. Antioxidants. 2014; 3: 671-83.

11. Kamtekar S, Keer V, Patil V. Estimation of phenolic content, flavonoid content, antioxidant and alpha amylase inhibitory activity of marketed polyherbal formulation. J Appl Pharm Sci. 2014; 4: 61-5.

12. Dehghan H, Sarrafi Y, Salehi P. Antioxidant and antidiabetic activities of 11 herbal plants from Hyrcania region, Iran. J Food Drug Anal. 2016; 24:179-88.

13. Lineweaver H, Burk D. The determination of enzyme dissociation constants. J Am Chem Soc. 1934; 56: 658-66.

14. Kilic I, Yesiloglu Y, Bayrak Y. Spectroscopic studies on the antioxidant activity of ellagic acid. Spectrochim Acta A Mol Biomol Spectrosc. 2014; 130: 447-52

15. Jakovljević VD, Milićević JM, Stojanović JD, Solujić SR, Vrvić MM. Antioxidant activity of ethanolic extract of Penicillium chrysogenum and Penicillium fumiculosum. Hem Ind. 2014; 68: 43-9.

16. Alam MN, Bristi NJ, Rafiquzzaman M. Review on in vivo and in vitro methods evaluation of antioxidant activity. Saudi Pharm J. 2013; 21: 143-52.

17. Paixão N, Perestrelo R, Marques JC, Câmara JS. Relationship between antioxidant capacity and total phenolic content of red, rosé and white wines. Food Chem. 2007; 105: 204-14.

18. El Bedawey A, Mansour E, Zaky M, Hassan AA. Characteristics of antioxidant isolated from some plant sources. Food Nutr Sci. 2010; 1: 5-12.

19. Matsui T, Ogunwande I, Abesundara K, Matsumoto K. Antihyperglycemic potential of natural products. Mini-Rev Med Chem. 2006; 6: 349-56.

20. Oboh G, Agunloye OM, Adefegha SA, Akinyemi AJ, Ademiluyi AO. Caffeic and chlorogenic acids inhibit key enzymes linked to type 2 diabetes (in vitro): a comparative study. J Basic Clin Physiol Pharmacol. 2015; 26: 165-70.

21. Escandón-Rivera S, González-Andrade M, Bye R, Linares E, Navarrete As, Mata R. $\alpha$-Glucosidase inhibitors from Brickellia cavanillesii. J Nat Prod. 2012; 75: 968-74. 
22. López-Angulo G, Montes-Avila J, Díaz-Camacho SP, Vega-Aviña R, Ahumada-Santos YP, Delgado-Vargas F. Chemical composition and antioxidant, $\alpha$-glucosidase inhibitory and antibacterial activities of three Echeveria DC. species from Mexico. Arab J Chem. 2014; n.v: n.p. doi: 10.1016/j.arabjc.2014.11.050.

23. Moradi-Afrapoli F, Asghari B, Saeidnia S, Ajani Y, Mirjani M, Malmir $\mathrm{M}$, et al. In vitro $\alpha$-glucosidase inhibitory activity of phenolic constituents from aerial parts of Polygonum hyrcanicum. DARU. 2012; 20: 37. doi: 10.1186/2008-2231-20-37.

24. Shukla S, Park J, Kim DH, Hong SY, Lee JS, Kim M. Total phenolic content, antioxidant, tyrosinase and $\alpha$-glucosidase inhibitory activities of water soluble extracts of noble starter culture Doenjang, a Korean fermented soybean sauce variety. Food Control. 2016; 59: 854-61.

25. Adiani V, Gupta S, Chatterjee S, Variyar PS, Sharma A. Activity guided characterization of antioxidant components from essential oil of Nutmeg (Myristica fragrans). J Food Sci Technol. 2015; 52: 221-30.

26. Mladěnka $P$, Macáková $K$, Filipský $T$, Zatloukalová L, Jahodár L, Bovicelli $\mathrm{P}$, et al. In vitro analysis of iron chelating activity of flavonoids. J Inorg Biochem. 2011; 105: 693-701.

27. Adjimani JP, Asare P. Antioxidant and free radical scavenging activity of iron chelators. Toxicol Rep. 2015; 2: 721-8.

28. Duh PD. Antioxidant activity of burdock (Arctium lappa Linne): its scavenging effect on free-radical and active oxygen. J Am Oil Chem Soc. 1998; 75: 455-61. 